\title{
Óbito
}

\section{SAMUEL GÓMEZ AGUIRRE (1937-2006) In memoriam}

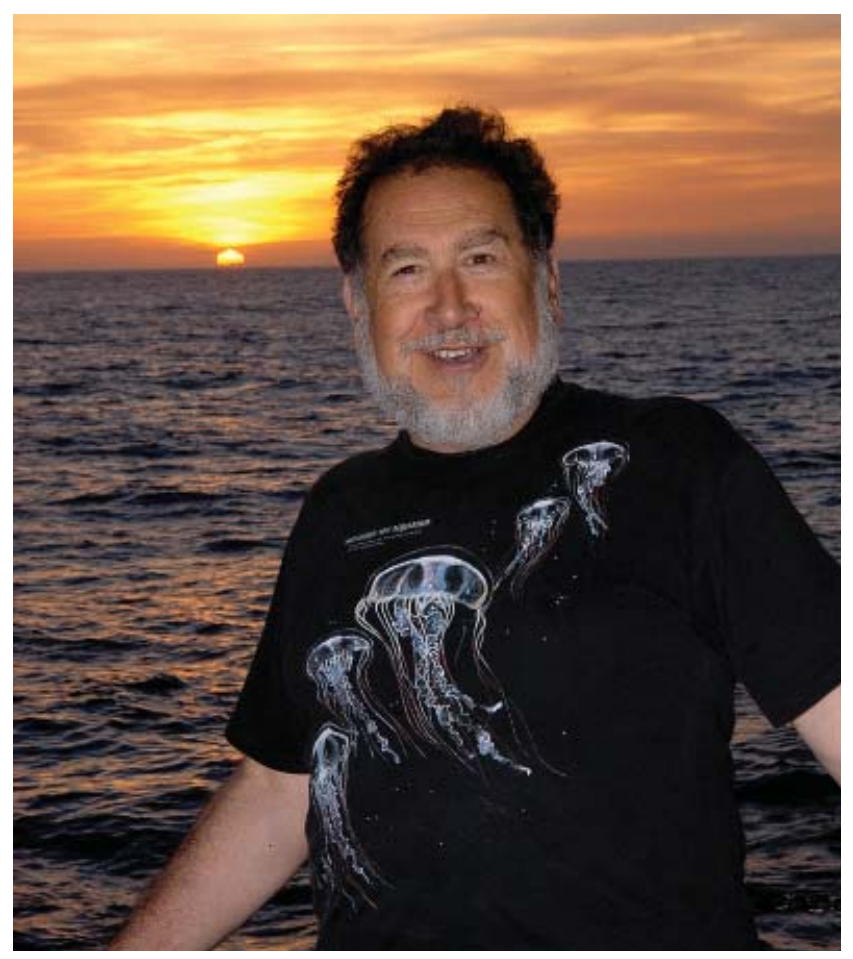

El 5 de abril de 2006, falleció el Dr. Samuel Gómez Aguirre. "Descanse en paz" es el deseo de todos quienes le conocimos.

Samuel nació en San Sebastián, Jalisco el 18 de marzo de 1937; más tarde su familia se mudó a Nayarit, en donde hizo sus estudios antes de ingresar a la Universidad Nacional Autónoma de México, en la Ciudad de México. En esta institución estudió la preparatoria, licenciatura, maestría y doctorado. Desde joven, en Nayarit trabajó en Telégrafos Nacionales para ayudar a costear sus estudios y así continuó cuando se mudó a la Ciudad de México. El final de la vida encontró a Samuel como investigador Titular del Instituto de Biología, mismo instituto que lo

Recibido: 12 abril 2007; aceptado: 28 abril 2007 vio nacer como académico.

Desde estudiante, Samuel estuvo fuertemente ligado a la biología marina y en particular al estudio de los organismos del plancton, al incorporarse al Laboratorio de Hidrobiología del mencionado instituto, donde hizo sus tesis con el Dr. Alejandro Villalobos, maestro que impulsó a un numeroso grupo de jóvenes en el campo de la planctonología. Sus tesis de licenciatura (Comportamiento estacional del plancton de la Laguna de Términos, Campeche) y doctorado (Comunidades planctónicas representativas de estuarios y lagunas costeras del noroeste de México) fueron trabajos precursores y constituyen lecturas obligadas para las siguientes generaciones.

El hombre trasciende por sus ideas, a través de sus acciones, creaciones y sobre todo por sembrarlas en las nuevas generaciones, entonces continuarán a través de 
los tiempos; éste es el caso de Samuel. Sus publicaciones (alrededor de 50 artículos científicos, 18 capítulos en libros y varios libros editados), clases en varias universidades, conferencias y diferentes actividades siempre estuvieron ligadas al plancton, campo del saber en el que trascendió de diferentes maneras, y que desde nuestro punto de vista, puede resumirse en los siguientes párrafos.

Fue pionero, pero sobre todo, impulsor del la planctonología. Impulsó junto con otros colegas la creación de La Sociedad Mexicana de Planctología y a nivel latinoamericano, impulsó la creación de la Asociación Latinoamericana de Investigadores en Ciencias del Mar.

Sin duda uno de los papeles mas importantes en su vida fue el de profesor, ya dictando cursos, ya dirigiendo tesis y como consecuencia, formando a un gran número de estudiantes, muchos de los cuales hoy se dedican a este campo de la investigación.

En la vida le ayudó su carácter firme y decidido, aunado a una gran nobleza y disposición para ayudar a quien se lo solicitase. Fue un hombre sin vicios, que se distinguió por su entrega al trabajo y a su familia, que fueron sus únicos y verdaderos objetivos en la vida.

Nuestra relación con Samuel inició, en el caso de César Flores en 1964, como compañeros realizando la tesis con el Dr. Alejandro Villalobos; junto con otros estudiantes iniciamos una serie de trabajos sobre el plancton de la zona arrecifal de Veracruz. En el caso de Sergio Licea, en 1965 inició su relación como alumno. Posteriormente ya en el año de 1969, formamos parte de un grupo que inició los estudios de las lagunas costeras del noroeste del país. Las relaciones se fortalecieron y se transformaron en amistad, que duró por siempre, por lo que ahora es un honor y privilegio escribir, aunque con nostalgia, estas líneas en su memoria, que expresan nuestro reconocimiento y admiración, tanto a la trascendente labor académica, como a la gran valía del colega, del maestro y sobre todo, del amigo.

César Flores-Coto y Sergio Licea-Durán.

Instituto de Ciencias del Mar y Limnología, Universidad Nacional Autónoma de México. 